\title{
A STUDY OF BUILDING A MODEL FOR THE DIMENSIONS OF ORGANIZATIONAL CULTURE THAT ARE IMPACT RELATED TO INCREASING THE EMPLOYEE'S PRODUCTIVITY OF PUBLIC SECTOR IN SAUD ARABIA
}

\author{
Feryal Abdullah Abdulrahman Al-Oumi ${ }^{1}$, Dr. Majed Al Doubi ${ }^{2}$ \\ ${ }^{1,2}$ Faculty of Business and Management, Al Medina International University, Kuala Lumpur, \\ Malaysia
}

Article DOI: $\underline{\text { https://doi.org/10.36713/epra8412 }}$

DOI No: 10.36713/epra8412

\begin{abstract}
This paper aims to Build model for the dimensions of organizational culture that are impact related to increasing employee productivity of public sector employees in Saudi Arabia, However Every organization has a unique culture, which shapes the employees' perspectives to a large extent. This model can set common general lines for these organizations, the researcher recommends future studies on establishing indicators to measure those dimensions according to their importance and to identify strengths and weaknesses in the productivity of public sector employees. The aim of this paper is to Build model for the dimensions of organizational culture that are impact related to increasing employee productivity including its subcomponents of public sector employees in Saudi Arabia.

KEYWORDS: Organizational culture, Dimensions of organizational culture, Employee productivity.
\end{abstract}

\section{INTRODUCTION}

This paper presents the findings from a 24-month project examining Organisational culture in the public sector in Employees of the Ministry of Human Resources branch in the Eastern Province in Saudi Arabia. The research project was coordinated by the researcher, in association with the branch in the Eastern Province of the Ministry of Human Resources. The project method is a descriptive survey, it involved three stages. The first stage entailed in-depth interviews with the senior managers, and employees from each of the organisational units participating in the project. The second stage consisted of a Collecting, sorting and analyzing the opinions of the participants and then classifying the information.
The final stage was It was about building dimensions of organizational culture that are directly related to increasing employee productivity, spatial environment Building a model for these dimensions with their sub-components.

\section{The Leaderships}

Today's competitive organizations demand leadership. Leadership is about behavior first and skills second. Strategic leaders have a vision, are able to influence followers, and are able to transform their vision into action. It all comes back to promoting positive expectations and having those expectations realized. [1] 


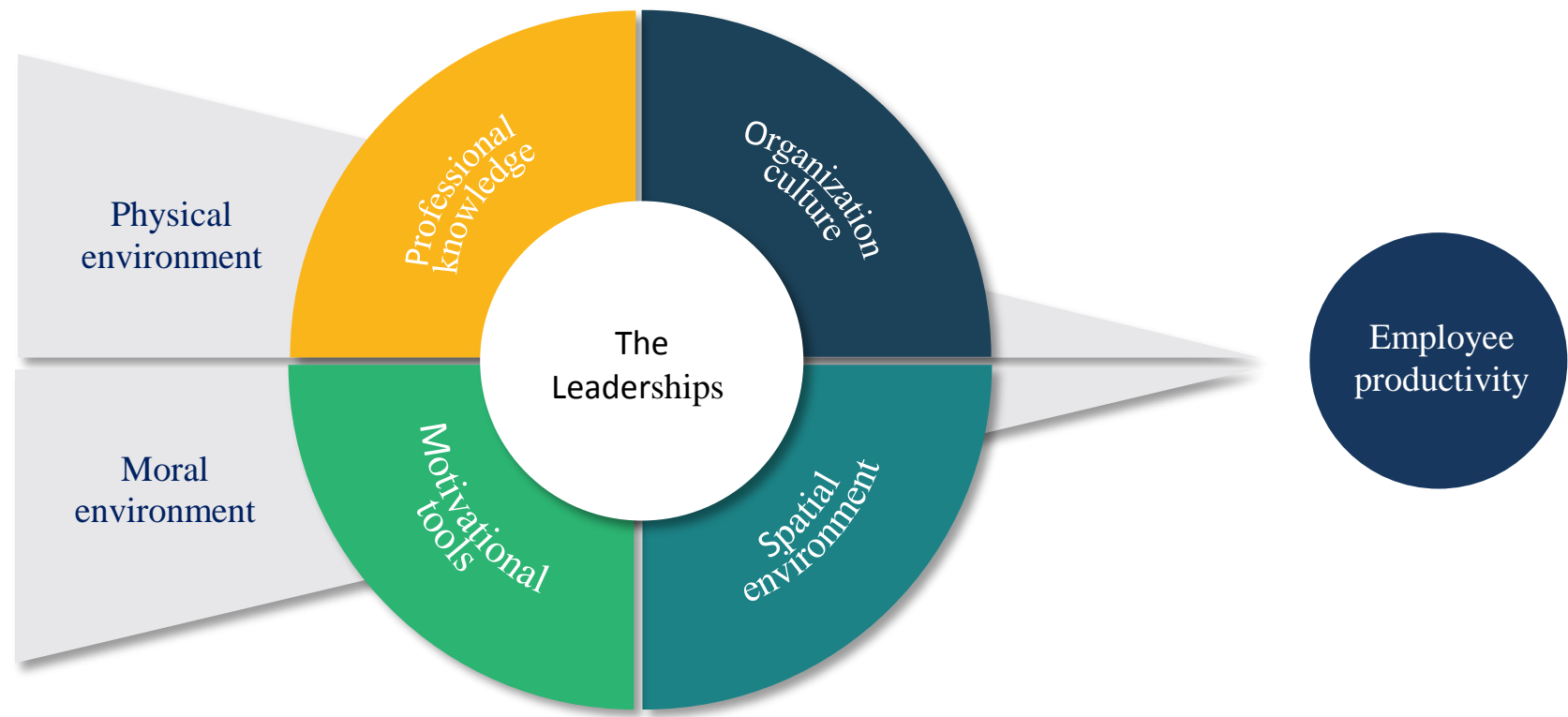

Fig.-1: Dimensions of organizational culture

Organization culture: Its mission, culture, goals, values, policies and procedures, and this component contributes to shaping the overall impression of the facility internally and externally.

Professional knowledge: Investing in human capital everything related to developing knowledge and skills for employee development personally, professionally, and socially.
Spatial environment: All material capabilities that provide a safe and stimulating workplace for employees and equipped according to their basic needs, and is considered their right.

Tools and motivational methods: Possible motivating tools and mean, for high and distinctive productivity for all, and it rises with the high evaluation of employee performance.

Fig.-2: Sub-components of the dimensions of organizational culture.

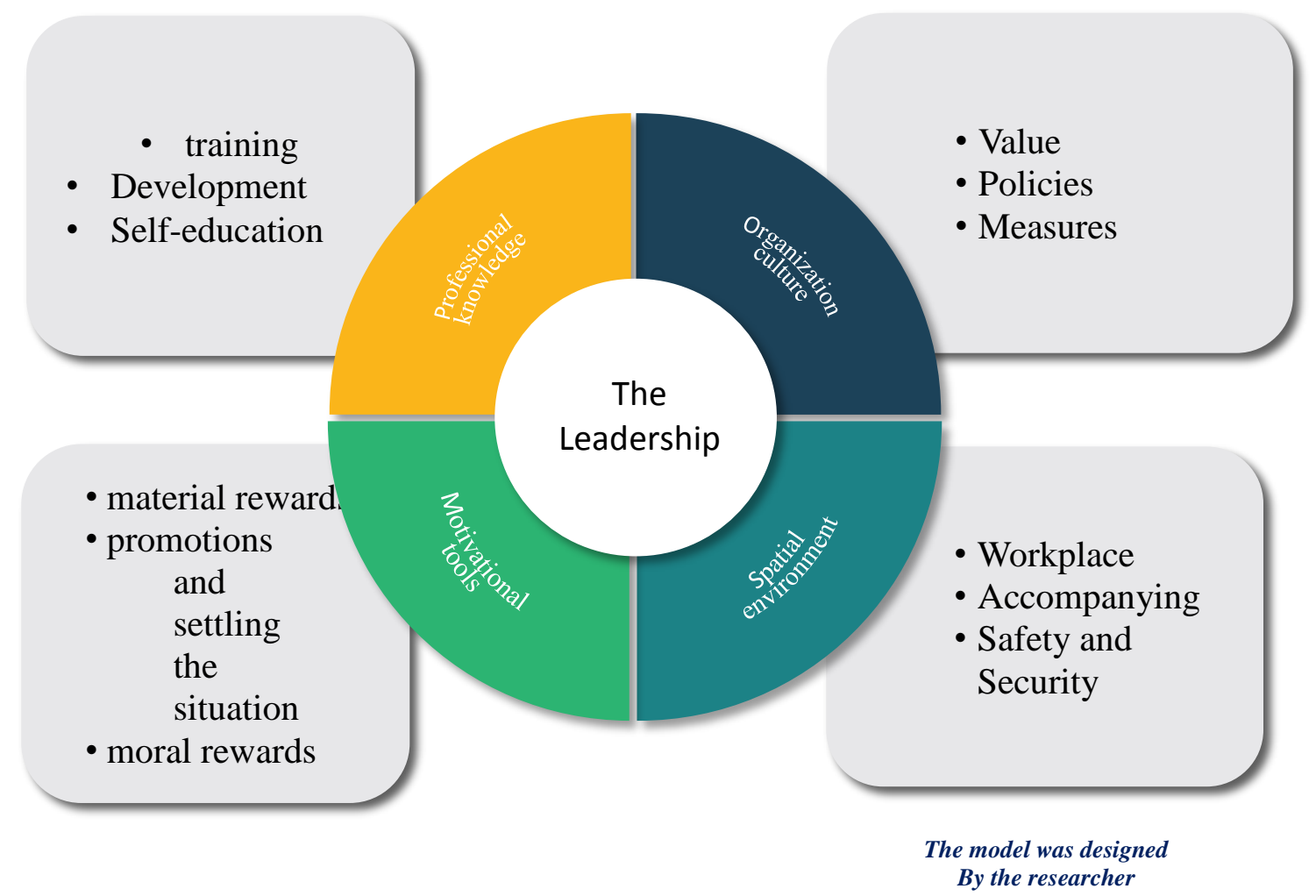




\section{Problem Status}

There are some survey studies that showed that the productivity of the Saudi employee working in the government sector is very low, which in turn affects the quality of government services provided.[2]

Therefore, the researcher seeks at this time to develop a model that includes the dimensions most influential in raising employee productivity based on the results of interviews with the study sample.

\section{LITERATURE REVIEW}

\subsection{The leadership}

The current study finds that leadership styles have a significant impact on organizational culture,[3]

\subsection{Organizational culture}

Organizational culture can manifest itself in a variety of ways, including leadership behaviors, communication styles, internally distributed messages and corporate celebrations. Given that culture comprises so many elements, it is not surprising that terms for describing specific cultures vary widely. Some commonly used terms for describing cultures include aggressive, customer-focused, innovative, fun, ethical, research-driven, technology-driven, processoriented, hierarchical, family-friendly and risk-taking. Because culture is difficult to define, organizations may have trouble maintaining consistency in their messages about culture. Employees may also find it difficult to identify and communicate about perceived cultural inconsistencies.[4]

Organizational culture is defined as shared values and basic assumptions that explain why organizations do what they do and focus on what they

focus on. [5], Organizational culture is defined as a firm's internal characteristics that play a determinant role in its long-term development. It represents how organization members interact with one another and how the organization associates with its stakeholders. In other words, a business' culture is a guidance that directs the operation, workflow and customer management within an organization.[3]

\subsubsection{Value, Policies, and Measures}

Employers have a vital role in perpetuating a strong culture, starting with recruiting and selecting applicants who will share the organization's beliefs and thrive in that culture, developing orientation, training and performance management programs that outline and reinforce the organization's core values and ensuring that appropriate rewards and recognition go to employees who truly embody the values.[4]

The productivity of the worker is affected by other factors related to the organizational status and nature of the work. While others believe that the root of the problem is due to the absence of a legal framework that regulates the process of clearing transactions.[2].

\subsection{Professional knowledge}

Applied economic studies that dealt with the subject of labor productivity determinants show that there are a set of economic, technical, organizational and social factors that affect the worker's productivity rate. As for the technical factors, they include scientific knowledge, or scientific level, and cognitive experience, enjoyed by the worker. The higher the educational and cognitive level of the worker, the higher his productivity, and vice versa.[2]

\subsubsection{Training, Development, and Self-education}

In the development of organizations, training plays a vital role, improving performance as well as increasing productivity, and eventually putting companies in the best position to face competition and stay at the top. This means that there is a significant difference between the organizations that train their employees and organizations that do not.. Training is a type of activity which is planned, systematic and it results in enhanced level of skill, knowledge and competency that are necessary to perform work effectively. There exists a positive association between training and employee performance. [6]

\subsection{Spatial environment}

The study then recommends that all elements of the physical office environment should be improved towards employee efficiency and productivity except the office temperature which was unanimously agreed to be conducive for the work environment. [7]

\subsection{Tools and motivational methods}

Some attribute the low productivity of the government employee to the low level of wages, andthus to the improvement of the level of productivity. Some controls and procedures for employment, salaries, promotions and others must be reviewed. [2]

\section{CONCLUSION}

This paper is Determining the dimensions of organizational culture that affect the productivity of employees in the public sector, and studies have proven the strong impact of each dimension. Studies have proven the effect of each dimension separately, and the researcher here calls for conducting empirical studies for this model and applying it to public sector employees and developing indicators that measure the impact of these dimensions on the productivity of the government employee, This model should enable organization members to evaluate the organization according to the main cultural dimensions and its subelements. 


\section{REFERENCES}

1. Nafei, Khanfar, Kaifi, 2011. Leadership Styles and Organizational Learning an Empirical Study on Saudi Banks in Al-Taif Governorate Kingdom of Saudi Arabia, doi:10.5430/jms. v3n1p2.

2. https://www.aleqt.com/2012/04/11/article_645764. html

3. Lam, L.; Nguyen, P.; Le, N.; Tran, K. The Relation among Organizational Culture, Knowledge Management, and Innovation Capability: Its Implication for Open Innovation. J. Open Innov. Technol.Mark. Complex. 2021, 7, 66.

4. doi.org/10.3390/joitmc7010066

5. https://www.shrm.org/resourcesandtools/toolsands amples/toolkits/pages/understandinganddeveloping organizationalculture.aspx.

6. Schneider, B., Gonz'alez-Rom'a, V., Ostroff, C. and West, M.A. (2017), "Organizational climate and culture: reflections on the history of the constructs in the journal of applied psychology", Journal of Applied Psychology, Vol. 102 No. 3, p. 468.

7. Sabir, R.I., Akhtar, N., Bukhari, Nasir, J. \& Ahmed, W. (2014). Impact of Training on Productivity of Employees: A Case Study of Electricity Supply $938 X$.
Company in Pakistan, International Review of Management and Business Research, Vol. 3 Issue.2, ISSN: 2306-9007.

8. Amofa, A. K., Yawson, M. D. T.-A., \& Okronipa, G. A. (2016). The Effect of the Physical Office Environment on Employee Productivity: The Case of Some Selected Banks in the Sekondi-Takoradi Metropolis, Ghana. ADRRI Journal (Multidisciplinary), 25(4), 24-36. Retrieved from https://journals.adrri.org/index.php/adrrij/article/vi ew/282.

9. Parker, R. and Bradley, L. (2000), "Organisational culture in the public sector: evidence from six Organisations", International Journal of Public Sector Management, Vol. 13 No. 2, pp. 125141. https://doi.org/10.1108/09513550010338773.

10. De Grip, A., \& Sauermann, J. (2013). The effect of training on productivity: The transfer of on-the-job training from the perspective of economics. Educational Research Review, 8, 28-36.

11. Andries De Grip, Jan Sauermann, The effect of training on productivity: The transfer of on-the-job training from the perspective of economics, Educational Research Review, Volume 8,2013, Pages 28-36, ISSN1747-

12. Cherian, J., Gaikar, V., Paul, R., \& Pech, R. (2021). Corporate Culture and Its Impact on Employees' Attitude, Performance, Productivity, and Behavior: An Investigative.Analysis from Selected Organizations of the United Arab Emirates (UAE). Journal of Open Innovation: Technology, Market, and Complexity, 7(1), 45. doi:10.3390/joitmc7010045. 